\title{
BIOG-BYWORD
}

\section{The Humanistic Value of Knowledge Economy and Law}

\author{
Wenhong Qu* \\ Jilin Province Veterans Service Center, Changchun 130022, China \\ *Corresponding author: Wenhong Qu, 1308418466@qq.com
}

\begin{abstract}
In order to explore the humanistic value of knowledge economy and law, this article analyzes the humanistic value by means of theoretical analysis. It first expounds the connotation of knowledge economy, then expounds from two aspects: the humanistic value of knowledge economy and the humanistic value of knowledge economy law. This article is meant for the perusal of relevant personnel.
\end{abstract}

Keywords: Knowledge economy; Humanistic value; Innovation

Publication date: October 2021; Online publication: October 29, 2021

\section{Introduction}

In short, knowledge economy is an economy based on knowledge. The formation of this concept is based on agricultural economy and industrial economy. It can be said that it is a major stage in the development of the world economic model. The era of knowledge economy has obvious characteristics, which are different from agricultural economy and industrial economy, including intelligent resource utilization, intangible asset investment, industrialization of knowledge utilization, sustainable economic development, globalization of knowledge economy, virtualization of enterprise development, widening per capita income gap, etc. Knowledge economy has injected new vitality into the development of modern society and can effectively promote the optimization of economic structure, rational utilization of resources, ecological environment protection, and so on. Knowledge economy itself is the product of human knowledge, and the corresponding high-quality human resources have naturally become important resources in the era of knowledge economy.

\section{Humanistic value of knowledge economy}

\subsection{Knowledge economy takes extraordinary knowledge as the main input}

Knowledge economy takes knowledge as the core production factor, and other production factors are gathered by knowledge to jointly create new values. To understand the essential characteristics of knowledge economy, it is necessary to define "knowledge" as a factor of production. Generally speaking, the concept of knowledge is broad and abstract (Jiaji Fu and Yuan Cheng, 1998). Lundvall and Johnson (1994) divided knowledge into four categories: know-what, know-why, know-how, and know-who. Among them, "know-what" is the knowledge about facts, while "know-why" is the scientific knowledge about natural laws and regulations. These two kinds of knowledge can often be encoded and obtained from words. "Know-how" is the knowledge about skills and ability, while "know-who" is the knowledge about who knows some kind of information. These two kinds of knowledge are often hidden in experience and can only be obtained through learning and understanding. 
Explicit knowledge is a kind of knowledge that can be expressed in language and through writing. It is divided into conventional explicit knowledge and supernormal explicit knowledge. Conventional explicit knowledge is the knowledge further summarized on the basis of previous knowledge, such as various textbooks of natural science and social science, whereas supernormal explicit knowledge is the knowledge first put forward when most people are still in an unknown state, such as Einstein's theory of relativity and Nash's game theory. Tacit knowledge is a kind of knowledge that cannot be expressed by language or through a writing system but is divergently expressed through personal experience, skills, interests, hobbies, talents, inspiration, passion, and other characteristics. Tacit knowledge is difficult to impart to others in an organization, so it is difficult to share and spread this kind of knowledge. Tacit knowledge can be divided into conventional tacit knowledge and supernormal tacit knowledge. Conventional tacit knowledge is the special skills, workmanship, and experience that ordinary people have, such as car repair skills. On the other hand, supernormal tacit knowledge refers to special talents, inspiration, interests, hobbies, and passions with economic and social pioneering value, such as the internal knowledge of inventors.

Knowledge economy needs not only the support of stock knowledge, but also the drive of incremental knowledge brought by knowledge innovation. Its core knowledge investment is no longer conventional knowledge in the traditional sense, but supernormal knowledge, especially supernormal tacit knowledge, which is determined by the special function of this kind of knowledge through knowledge innovation. Supernormal tacit knowledge is the primitive impetus for innovation. Its essence includes knowledge with future exploration, hidden latent knowledge, behavior embodied knowledge, and dynamic creative knowledge. The greatest characteristic of supernormal implied knowledge is imagination; that is, on the basis of perceiving reality, new things are predicted through abstraction and conjecture, and new things are created out of nothing. This is the source of all knowledge innovation. Human beings have cognitive limitations, especially the lack of understanding of supernormal tacit knowledge.

\subsection{Knowledge economy promotes an all-round development}

Compared with the agricultural economy and industrial economy, which mainly solve the material needs of consumers, such as food, clothing, housing, and transportation, knowledge economy weighs more on self-development, social needs, and achievements of consumers. It includes knowledge intensive industries, such as biological genes, big data, and artificial intelligence, which do not only ensue a healthier and comfortable life for people, but also facilitate social interaction, cooperation, and autonomy among people, as well as the realization of individual interests, hobbies, and creative inspiration. On the platform of developing a new generation of information technology and biotechnology, the subject of a natural person can have many forms of existence, such as digital human, virtual human, genetic human, and so on. The innovator group represented by scientists and entrepreneurs has the positive externality of human capital, improves the human capital level as a whole, as well as promotes economic and social development to the greatest extent. Without the new knowledge created by innovators, it is difficult to improve the quality of human capital and social welfare of a large number of ordinary workers. The traditional economic philosophy, which pursues the maximization of personal interests, is gradually giving way to the economic philosophy of people's mutual benefit under the background of knowledge economy.

\subsection{Knowledge economy promotes innovation}

The socialist system with Chinese characteristics has a scientific and complete system. From the perspective of the economic system, public ownership is the main body, and the economy of various forms of ownership develops together; the distribution according to work and production factors are linked; the market plays a decisive role in the allocation of resources and gives better play to the role of the government. All these 
have fully mobilized the enthusiasm of all sectors of society, greatly liberated and developed social productive forces, as well as played an indelible role in China's economic development. However, with the continuous development of the economy, the disadvantages of the science and technology system in China have begun to appear. In the era of scientific and technological innovation in which the role of human capital has exceeded material capital, the mechanism system, that tilted the distribution of resources and income to material capital due to the important role of the latter in the past economic development, cannot meet the needs of the development of scientific and technological innovation, which also has institutional obstacles. The core element of scientific and technological innovation is the people. The strategy of strengthening the country through science and technology is actually a strategy led by talents. The motivation of personal innovation comes from the effective use and rational allocation of human capital elements, such as knowledge and skills invested in innovation, and finally obtain corresponding and reasonable benefits. The existing scientific and technological innovation system and mechanism in China are not perfect, the talent evaluation system and management system are unreasonable, the independent talent flow mechanism is not smooth, the market mechanism does not determine the fairness and rationality of talent innovation income, the scientific and technological reward system of the government lacks incentives, and the society lacks full understanding and respect for the value created by intellectual labor. This does not only lead to the ineffective use of the innovative passion and creativity of scientific and technological innovators, but also hinder the personal development of talents and social innovation to drive economic development.

\section{Humanistic value of knowledge economy law}

\subsection{Intellectual property rights promote the development of knowledge economy}

The current industrial economy has brought material abundance to mankind. Compared with knowledge economy, industrial economy focuses on scale and replication; however, replication can only lead to the improvement of quantity. In order to bring about a qualitative leap, the only way is through innovation, and knowledge economy is characterized by innovation. Therefore, the qualitative leap of the human society needs to be triggered by knowledge economy. The three waves of human experience are all created by revolutionary innovation, and innovation is the only way to ensure the vitality of human progress. The personal microcomputer invented by Steve Jobs and Stephen Gary Wozniak in 1976 as well as the operating system, CP/M-86 (the predecessor of Microsoft's personal computer operating system), creatively developed by Seattle Computer in 1979 brought about the popularization of computer technology in the human society. In addition, the innovation and popularity of the internet, which accepted the TCP/IP protocol in 1982, has led to tremendous advances in knowledge acquisition. Innovation makes human progress, which is also the only way to continuously ensure economic vitality in the current era of knowledge economy. Therefore, only by ensuring lasting innovation can human beings make eternal progress. Incentives and restraints are the most effective measures to ensure that people's behaviors are in line with the intention of managers. At present, the state, as a macroeconomic manager, should regulate human economic behavior through incentives and restraints to ensure lasting innovation and maintain economic vitality; that is, to use interests to encourage innovators to advance bravely and restrain illegal acts that damage the interests of innovators.

\subsection{Public protection of intellectual property}

In terms of public protection, there are two types of protection: first protection and second protection. The first protection refers to the confirmation or grant of intellectual property rights according to law; that is, to determine the protection scope of intellectual property rights. The second protection refers to the protection 
provided by the law to the obligee after the infringement of the intellectual property rights obtained according to law. The second protection of public power is the most important protection, which is clearly stated in Article 9 of the Outline of the National Intellectual Property Strategy. The protection of intellectual property rights provided by the state public power includes civil protection, criminal protection, and administrative protection.

In the second protection, the key lies in determining the infringement of intellectual property. The infringement of simple intellectual property can be proved by both parties. However, for complex infringement, especially the intellectual property formed by creative intellectual activities, such as patent right, trade secret right, copyright, and adjacent right, it is necessary to rely on technical experts and literary artists in relevant fields based on their professional knowledge in those fields, conduct judicial appraisal of the intellectual property involved (including judging whether the intellectual property is novel, whether the intellectual property is common knowledge or industry practice of professionals in the field it belongs to, whether it can be easily obtained without paying a certain price, whether the infringing intellectual property is identical or substantially identical with the infringed intellectual property, etc.), as well as determine whether the infringement is serious. Then, with the help of asset appraisal and judicial appraisal, the value of infringement damage can be evaluated, so as to help the court determine the punishment and the amount of civil compensation in the implementation of the public protection of intellectual property rights.

\section{Conclusion}

In summary, the theme of knowledge economy is people oriented. Only human development can promote economic progress. The most important thing of knowledge economy is to realize human education and innovation on the premise of human development.

\section{Disclosure statement}

The author declares that there is no conflict of interest.

\section{References}

[1] Guo JW, Huang KT, 2020, Discussion on the Development of Labor Value Theory in the Era of Knowledge Economy. Guangxi Quality Supervision Guide Periodical, (12): 181-182.

[2] Tian SJ, 2020, Intellectual Property Protection of Business Model Innovation Elements. Shandong University.

[3] Zhaohe ST, 2020, Analysis on the Value of Human Resources in the Era of Knowledge Economy. Fortune Today (China Intellectual Property), (05): 167-168.

[4] Lin X, 2020, Analysis on the Value of Human Resources in the Era of Knowledge Economy. China Circulation Economy, (05): 108-109.

[5] Ma ZF, 2019, Knowledge Economy and Enterprise Intellectual Property Management, Shanghai People's Publishing House, 405.

[6] Shi ZG, 2019, Patent Creates More Value in the Era of Knowledge Economy. Medicine Economic News, (007).

[7] Sun N, 2015, Discussion on the Legal Protection of Intellectual Property Rights under the Background of Knowledge Economy. Productivity Research, (01): 152-154. 